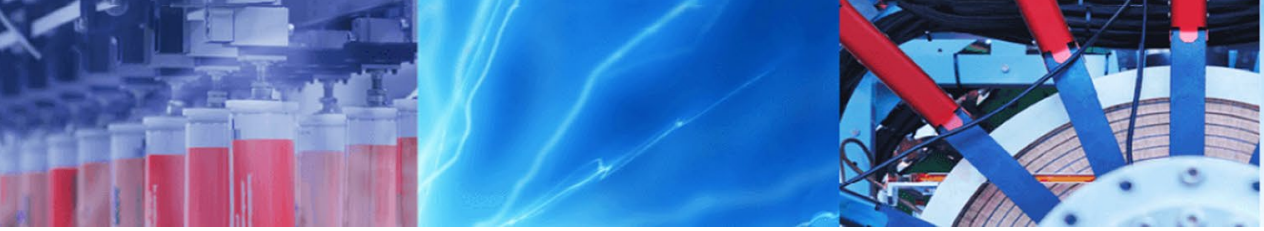

Research Article

\title{
Investigation of the effect of impact direction on Schmidt rebound values by multivariate regression and neuro-fuzzy model
}

\author{
Hasan Karakul ${ }^{1}$
}

Received: 12 August 2020 / Accepted: 28 September 2020 / Published online: 10 October 2020

(c) Springer Nature Switzerland AG 2020

\begin{abstract}
Schmidt hammer test is a nondestructive test used in rock characterization and estimation of mechanical properties of rocks. It is an important advantage that the experiment can be carried out for different impact directions. However, a normalization should be performed on the test results because of variation of effect of gravitational forces on rebound value. On the other hand, some weak, highly porous and weathered rocks have different energy absorbance levels that may not confirm the assumption of normalization formula of the suggested method. So, in this study it is aimed to examine the prediction performance of suggested normalization formulation for weak and highly porous rocks. For this purpose, Schmidt hammer tests for five different impact directions were performed on eight different rock types. The test results indicated that, in general, the rebound values obtained for an impact direction other than horizontal can be converted to the rebound value of horizontal impact direction with a high accuracy by using suggested normalization formula and/or chart. However, existence of some exception was also determined for weak and highly porous rock types. Multivariate regression analyses and adaptive-neuro-fuzzy inference system (ANFIS) were used to explain the variation of ratio between the normalized and tested rebound values for rock types used in this study. The results obtained from statistical and soft computing methods showed that the ratio between the normalized and tested rebound values is predictable and higher for weak and highly porous rock types.
\end{abstract}

Keywords Schmidt hammer test · Impact direction - Energy absorbance level · Multivariate regression analysis · Soft computing methods

\section{Introduction}

Schmidt hammer test is a nondestructive test method which is extensively used for the estimation of geomechanical parameters (such as uniaxial compressive strength and modulus of elasticity) in rock engineering applications and rock material characterization. The test can be applied both in field and laboratory due to portable nature of the hammer. The nondestructive nature of the experiment ensures that deformations remain within elastic limits and there is no sample loss. On the other hand the level of impact energy limits the usage range interval of hammer.

Although it is considered as an important advantage that the experiment can be used both in the laboratory and in the field, this advantage also includes some limitations. The existence of different inclinations of geological layers and structural features in the field makes it inevitable to perform the Schmidt hammer tests in different directions. However, the rebound values obtained from different impact directions are varied due to gravitational forces. So, it is essential to eliminate the different effects of external forces on the test results. In order to

Hasan Karakul, hasan.karakul@ikc.edu.tr| 'Department of Petroleum and Natural Gas Engineering, İzmir Kâtip Çelebi University, İzmir, Turkey. 
take into consideration the impact direction-dependent gravitational effect, Basu and Aydın [5] conducted a study based on theoretical normalization approach and derived equations to transform the rebound values obtained from nonhorizontal direction to the rebound values obtained from horizontal impact direction. The authors derived normalization curves in various impact directions for different ( $L$ and $N$ type) Schmidt hammers. The authors also used anvil and plaster materials to confirm the theoretical formulations and stated that theoretical formulations and experimental results are compatible with each other. Basu and Aydın [5] also noted that the theoretical formulation is based on the proportionality between square of rebound velocity and impact energy, and this assumption may not be satisfied for some weak and weathered rocks due to huge variation of energy absorbance level of tested surfaces of rocks. Aydın and Basu [5] expressed that as the Schmidt hammer test applied on a rock surface, the piston released on the plunger and creates an impact energy. Aydın and Basu [5] also stated that while some of this energy absorbed by rock material due to plastic deformation on tested surface and converted to heat and sound, the remaining energy is responsible for piston rebound. Szilagyi [23] stated that reflected compression wave reaches to the plunger and makes the piston (hammer mass) to rebound and stressed that the rebound mainly due to elastic strain induced by hammer impact. On the other hand, Li et al. [15] stressed that rebound of Schmidt hammer is a function of unloading coefficient $(\gamma)$ and dimensionless values $(\beta)$ of tested rocks. While the rebound value is inversely proportional with unloading coefficient, increment in dimensionless value gives reason to increase in rebound value. Li et al. [15] also expressed that $\beta$ values are low for soft rocks and $\gamma$ values approach to $\infty$ for low strength rocks. So it can be understood that soft and low strength rocks have low rebound values due to low $\beta$ and high $\gamma$ parameters. The inability to derive a single relationship valid for all rocks [25] is due to the these differences of rocks.

Impact energy of Schmidt hammer is a function of impact direction because of existence of gravitational forces. As stressed by Basu and Aydın [5], the differences between the highest and lowest impact energy for $L$ - and $\mathrm{N}$-type Schmidt hammers are 0.1 and $0.3 \mathrm{Nm}$, respectively. As it is known, 0.735 and $2.207 \mathrm{Nm}$ impact energies are used in L- and $\mathrm{N}$-type Schmidt hammers, respectively. So it can be assessed as an indicator of effect of impact energy on rebound values. Up to date, there are a few studies Ayday and Göktan [3], Aydın and Basu [4], Buyuksagis and Goktan [6] focused on comparison of rebound values obtained by L- and N-type hammers. Ayday and Göktan [3] determined a statistically reliable linear relationship between rebound numbers obtained by $\mathrm{L}$ - and $\mathrm{N}$-type
Schmidt hammers for 19 different rock types and stated that rebound number obtained from $\mathrm{N}$-type Schmidt hammer is significantly higher than the rebound number of L-type hammer. Aydın and Basu [4] found higher rebound values for $\mathrm{N}$-type Schmidt hammer by testing 40 granitic core specimens. In accordance with previous studies, Buyuksagis and Goktan [6] also determined lower rebound values by using L-type Schmidt hammer for 27 different rock types.

Li et al. [16] expressed that while the reflected energy is decreased due to increment in impact load, absorbed energy level is increased for siltstone samples. The authors also stated that maximum value of absorbed energy is obtained near the axial stress close to elastic limit of siltstone. Li et al. [16] also stated that some defects inside the rocks such as microcracks and fissures can be assessed as reflection surfaces for stress waves when the impact applied on rock specimen. So it can be inferred from the previous studies that the rebound value is inversely proportional to the adsorbed energy which is increased due to impact load and affected by defects in rock samples. So as it was also stressed by Basu and Aydın [5] the most critical parameter for weak rocks is the energy absorbance level which can violate the prediction of horizontal rebound value from the rebound values determined for different impact directions by using normalization curves. The motivation of this study is to investigate the performance of the suggested normalization procedure on Schmidt rebound values for different rock types. So, by considering the previous studies and deficiencies emphasized above, this study aimed to investigate the variation of rebound values due to impact direction for different rock types. In accordance with this purpose, Schmidt hammer tests were conducted on prismatic rock block specimens prepared from various rock types with five different impact directions. The normalization procedure suggested by Basu and Aydın [5] and ISRM [10] was performed on the test results to determine the prediction performance of normalization formulation and curves. Some physical tests (porosity, unit weight) were also performed, and the test results were used in evaluation of rebound values obtained from Schmidt hammer tests. Then, the effect of impact direction on the results was assessed by using multivariate regression analyses and soft computing methods.

\section{Laboratory experiments}

In order to examine the variation of energy absorbance level, 8 different rock types with the origin of sedimentary, volcano-sedimentary, volcanic and metamorphic were used in this study. The rock blocks were collected from stone processing plants and have cubic shape with 
a approximately $20-25 \mathrm{~cm}$ length of edge. The rock blocks do not have any weakness planes such as bedding, laminations and foliation planes. In accordance with the aim of the study, Schmidt hammer tests and some physical tests (porosity and unit weight) were performed on rock blocks and rock cores with NX diameter, respectively. L-type Schmidt hammer was used in this study by considering its effectiveness on weak and low strength and porous rocks as stressed by ISRM [11]. In Schmidt hammer tests, tests were performed on surfaces of prismatic rock block specimens at right angles to the surface. In total, 20 individual tests were performed on rock samples and average rebound value of tested surfaces was obtained. Schmidt hammer tests were carried out on rock blocks for five different impact directions $\left(+90^{\circ},+45^{\circ}, 0^{\circ},-45^{\circ},-90^{\circ}\right)$ by considering the different effects of gravitational forces on rebound values for different impact directions, Fig. 1. The tests on different impact directions were performed by using a portable metal table with a circular hole in the middle. The rock blocks were placed on this metal table, and preferred orientation was satisfied. The experiments were conducted by considering the methods suggested by ISRM [10] and [11]). The results of Schmidt hammer, porosity and unit weight tests are given in Table 1. The normalization procedure was applied on the test results to obtain the equivalent rebound value in the horizontal direction as suggested by Basu and Aydın [5], and the normalized values are also given in Table 1.

The normalized rebound value was calculated by using Eq.(1) as suggested by [5].

(a)

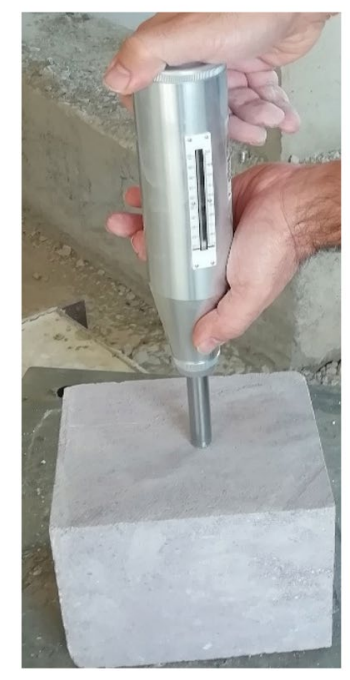

Fig. 1 a An overview of Schmidt hammer test, b five different impact directions used in this study
$R_{h}=\sqrt{\frac{V_{2}^{2}}{V_{1}^{2}} \times 100}$

where $V_{1}$ is the initial velocity of the piston as the instant piston touches the plunger and $V_{2}$ is the rebound velocity of the piston.

$V_{1}$ can be calculated by using the energy balance equation for first plunger contact and at maximum rebound given in Eq.(2) and Eq.(3), respectively [5].

$0.5 k x_{1}^{2}+M g x_{1} \cos (90-\theta)=0.5 \mathrm{M} \mathrm{V} v_{1(\theta)}^{2}$

$0.5 k x_{2(\theta)}^{2}+M g x_{2(\theta)} \cos (90-\theta)=0.5 \mathrm{M} \mathrm{V}_{2(\theta)}^{2}$

where $x_{1}$ is the maximum stretch of spring, $x_{2}$ is stretch of spring at maximum rebound, $M$ is mass of piston, $\theta$ is impact direction angle.

$V_{1}$ and $V_{2}$ can be determined by using Eq.(4) and Eq.(5), respectively [5].

$V_{1}^{2}=\frac{k x_{1}^{2}}{M}$

$V_{2}^{2}=\frac{V_{2(\theta)}^{2}\left(0.5 k x_{1}^{2}\right)}{\left(0.5 k x_{1}^{2}\right)+M g}$

So it can be understood from Eq. 5 that the rebound value for a specific impact direction other than $0^{\circ}$ depends on $V_{2(\theta)}$ value, $E_{\text {impact }}(0,735 \mathrm{Nm}$ for L-type Schmidt hammer) and $M g$ parameters. So the variation on rebound values is mainly controlled by $V_{2(\theta)}$ as $E_{\text {impact, }} M$ and $g$ are constants for L-type Schmidt hammer. On the other hand $V_{2(\theta)}$ is function of rebound value obtained for a specific impact direction and the some constants $\left(k, M, g\right.$ and $\left.x_{1}\right)$. So the normalization procedure applied on rebound values for a specific impact direction gives same results for different rock types if their Schmidt rebound values are same. However, as stated by Basu and Aydın [5] some weak and porous rocks have energy absorbance values different from other rock types. There are reasonable correlations between different hardness measurement methods (such as Schmidt, Shore and Leeb hardness tests) as stated by Çelik and Çobanoğlu [7].

Gilardi and Sharf [8] stated that the coefficient of restitution, which is closely related to the Schmidt rebound values (Peng, Ansari et al. [1, 20]), decreases as a result of increment in impact velocity and the level of this variation is controlled by material behavior (elastic, elastoplastic and perfectly plastic). The coefficient of restitution is equal to 1 for the perfectly elastic material and 0 for the perfectly plastic impact. So it can also be inferred that when the 
Table 1 Laboratory test results and statistics

\begin{tabular}{|c|c|c|c|c|c|c|c|c|}
\hline \multirow[t]{3}{*}{ Rock type } & \multicolumn{6}{|c|}{ Schmidt rebound value, $R$} & \multirow{3}{*}{$\begin{array}{l}\text { Unit weight, } \\
\gamma\left(\mathrm{kN} / \mathrm{m}^{3}\right)\end{array}$} & \multirow[t]{3}{*}{ Porosity, n (\%) } \\
\hline & \multicolumn{6}{|c|}{ Impact direction angle $(\theta)$} & & \\
\hline & $+90^{\circ}$ & $+45^{\circ}$ & $0^{\circ}$ & $-45^{\circ}$ & $-90^{\circ}$ & & & \\
\hline \multicolumn{9}{|l|}{ Andesite } \\
\hline Mean & & $41.6(45.0)$ & $\begin{array}{l}43.1 \\
(45.5)\end{array}$ & $\begin{array}{l}45.0 \\
(45.0)\end{array}$ & $\begin{array}{l}47.3 \\
(44.4)\end{array}$ & $\begin{array}{l}48.7 \\
(44.4)\end{array}$ & 24.5 & 3.9 \\
\hline Std dev. & & 0,8 & 0,8 & 0,9 & 0,8 & 0,6 & 0,2 & 0.6 \\
\hline Number & & 20 & 20 & 20 & 20 & 20 & 10 & 10 \\
\hline \multicolumn{9}{|l|}{ Travertine-1 } \\
\hline Mean & & $\begin{array}{l}46.3 \\
(49.4)\end{array}$ & $\begin{array}{l}46.9 \\
(49.2)\end{array}$ & $\begin{array}{l}49.1 \\
(49.1)\end{array}$ & $\begin{array}{l}51.3 \\
(48.6)\end{array}$ & $\begin{array}{l}52.5 \\
(48.6)\end{array}$ & 23.7 & 3.4 \\
\hline Std dev. & & 0,6 & 0,5 & 0,9 & 0,8 & 0,6 & 0.2 & 0.7 \\
\hline Number & & 20 & 20 & 20 & 20 & 20 & 10 & 10 \\
\hline \multicolumn{9}{|l|}{ Limestone } \\
\hline Mean & & $\begin{array}{l}39.5 \\
(43)\end{array}$ & $\begin{array}{l}41.1 \\
(43.6)\end{array}$ & $\begin{array}{l}42.2 \\
(42.2)\end{array}$ & $\begin{array}{l}45.3 \\
(42.3)\end{array}$ & $\begin{array}{l}46.8 \\
(42.4)\end{array}$ & 22.0 & 10.7 \\
\hline Std dev. & & 0,6 & 0,3 & 0,4 & 0,4 & 0,5 & 0.2 & 0.4 \\
\hline Number & & 20 & 20 & 20 & 20 & 20 & 10 & 10 \\
\hline \multicolumn{9}{|l|}{ Tuff-1 } \\
\hline Mean & & $\begin{array}{l}15.3 \\
(19.8)\end{array}$ & $\begin{array}{l}16.8 \\
(20.1)\end{array}$ & $\begin{array}{l}19.5 \\
(19.5)\end{array}$ & $\begin{array}{l}23.3 \\
(20.9)\end{array}$ & $\begin{array}{l}25.9 \\
(21.1)\end{array}$ & 14.3 & 20.3 \\
\hline Std dev. & & 0,3 & 0,6 & 0,5 & 0,5 & 0,6 & 0.1 & 0.6 \\
\hline Number & & 20 & 20 & 20 & 20 & 20 & 10 & 10 \\
\hline \multicolumn{9}{|l|}{ Marble } \\
\hline Mean & & $\begin{array}{l}50.5 \\
(53.4)\end{array}$ & $\begin{array}{l}51.2 \\
(53.3)\end{array}$ & $\begin{array}{l}53.3 \\
(53.3)\end{array}$ & $\begin{array}{l}55.1 \\
(52.6)\end{array}$ & $\begin{array}{l}56.6 \\
(53.0)\end{array}$ & 26.3 & 0.9 \\
\hline Std dev. & & 0,7 & 0,4 & 0,5 & 0,5 & 0,6 & 0.1 & 0.2 \\
\hline Number & & 20 & 20 & 20 & 20 & 20 & 10 & 10 \\
\hline \multicolumn{9}{|l|}{ Tuff-2 } \\
\hline Mean & & $\begin{array}{l}36.4 \\
(40.0)\end{array}$ & $\begin{array}{l}37.9 \\
(40.6)\end{array}$ & $\begin{array}{l}40,0 \\
(40.0)\end{array}$ & $\begin{array}{l}44.4 \\
(41.3)\end{array}$ & $\begin{array}{l}46.3 \\
(41.8)\end{array}$ & 18.7 & 17.3 \\
\hline Std dev. & & 0,6 & 0,4 & 0,7 & 0,7 & 0,8 & 0.4 & 0.8 \\
\hline Number & & 20 & 20 & 20 & 20 & 20 & 10 & 10 \\
\hline \multicolumn{9}{|l|}{ Travertine-2 } \\
\hline Mean & & $\begin{array}{l}37.5 \\
(41.1)\end{array}$ & $\begin{array}{l}38.2 \\
(40.8)\end{array}$ & $\begin{array}{l}40.4 \\
(40.4)\end{array}$ & $\begin{array}{l}43.2 \\
(40.0)\end{array}$ & $\begin{array}{l}44.7 \\
(40.1)\end{array}$ & 23.1 & 4.1 \\
\hline Std dev. & & 0,4 & 0,4 & 0,7 & 0,8 & 0,5 & 0.2 & 0.4 \\
\hline \multicolumn{9}{|l|}{ Ignimbrite } \\
\hline Mean & & $\begin{array}{l}31,6 \\
(35.5)\end{array}$ & $\begin{array}{l}32,9 \\
(35.7)\end{array}$ & $\begin{array}{l}36,1 \\
(36.1)\end{array}$ & $\begin{array}{l}40,6 \\
(37.3)\end{array}$ & $\begin{array}{l}42,5 \\
(37.7)\end{array}$ & 16,0 & 23.7 \\
\hline Std dev. & & 0,6 & 0,7 & 0,8 & 0,5 & 1,1 & 0.4 & 1.1 \\
\hline Number & & 20 & 20 & 20 & 20 & 20 & 10 & 10 \\
\hline
\end{tabular}

* Normalized Schmidt rebound values obtained for different impact direction are given in parenthesis impact energy was increased, the decrement level in the coefficient of restitution will be higher for plastic materials than elastic materials. So it is clear that the Schmidt hammer rebound values are sensitive to variation of impact energy for weak and porous materials.

The laboratory test results given in Table 1 also confirmed this approach. The normalized values calculated by using the rebound values obtained from $-45^{\circ}$ to $-90^{\circ}$ impact directions for three weak and high porosity rocks (Tuff-1, Tuff-2 and Ignimbrite) include some deviations from theoretical normalization values. It can be seen from Table 1 that the difference between the normalized rebound values obtained from $-45^{\circ}$ to $-90^{\circ}$ impact directions and horizontal rebound value was found between 
1.5 and 2. As also stated by Basu and Aydın [5], the lower impact energies valid for upward impact directions are responsible from this deviation. While downward impacts created more damage (plastic strain) on tested surface, the impacts created with upward directions formed less damage (plastic strain), so the normalized rebound value was calculated higher than the theoretical normalized values. However, this is not valid for high strength rock, because the damage created by hammer impact is negligible.

\section{Statistical analyses}

As it can be understood from normalization formulations and curves suggested by Basu and Aydın [5] and ISRM [10], the variation on rebound number values between different impact directions is low for hard and high strength rocks and high for soft, porous and low strength rocks. The results of this study also confirm this general trend. However, it should be also noted that there is a deviation between normalized rebound values for upward impact directions $\left(-45^{\circ}\right.$ and $\left.-90^{\circ}\right)$ and horizontal rebound value for rocks with low hardness and high porosity (Ignimbrite, Tuff- 1 and Tuff-2) according to results of this study. So as also stated by Basu and Aydın [5], some weak and porous rocks have rebound values deviated from normalized values. In order to explain this deviation, multivariate regression and ANFIS models were performed in this study. In order to avoid negative angle values in the statistical and ANFIS analyses, the transformation of $\theta_{s}=90-\theta$ was performed on the values of impact directions.

The essential parameters used in analytical normalization formulation are Schmidt hammer rebound and impact direction. So these are used as independent variables in multivariate regression analyses. However, the dependent variable is selected as $R_{\text {normalized }} / R_{\text {test }}$. So, first of all the normalization procedure as suggested by Basu and Aydın [5] and ISRM [10] was applied on rebound values and then $R_{\text {normalized }} / R_{\text {test }}$ was calculated and used as dependent variable in multivariate statistical analyses. Multivariate regression analysis produced the following equation with a high coefficient of determination. The reliability of multivariate regression equation is examined by F-test Table 2 , and a very low significance value $\left(p=1.510^{-25}\right)$ was obtained.
So the following equation was determined as statistically reliable based on F-test results.

$\frac{R_{\text {normalized }}}{R_{\text {test }}}=0,001468$ Impact direction $+0,020229 R_{\text {test }} R^{2}=0,95$

\section{ANFIS modeling}

Soft computing analysis is preferred by engineers recently by considering the complex, nonlinear responses of engineering applications in soil or rocks (Zhang et al. [26]). As a hybrid soft computing method, ANFIS method was used in different engineering areas by a great number of investigators (such as Jang and Sun, [13], Rezazadeh et al. [22], Mishra and Mohanty, [19], Mathur et al. [17], Petkovic et al. [21]). On the other hand, ANFIS was previously used in a few studies (Gökçeoğlu et al. [10], Armaghani et al. [2], Umrao et al. [24], Jing et al. [14], Jalali et al. [12]) to predict the geomechanical parameters of rocks.

So, in addition to multivariate regression analysis, ANFIS was also used in this study to estimate the $R_{\text {normalized }} / R_{\text {test }}$ ratio. This system is especially useful to create a model for which there exist required input and output data (MathWorks, [18]). ANFIS makes it possible to edit membership functions based on experimental data. ANFIS modeling was constructed by using MATLAB software. In ANFIS modeling, two input parameters (impact direction and Schmidt hammer rebound) and one output parameter ( $R_{\text {normalized }} /$ $R_{\text {test }}$ ) were used. While $75 \%$ of the experimental data were used as training data, the remaining portion $(25 \%)$ was used as testing data.

In constructing the neuro-fuzzy model, two hyperparameters (number of membership function and membership function type) were considered. It can be seen from Table 3 that the best model (the lowest RMSE) was determined with Gaussian-type membership function. The optimum numbers of membership function were also obtained as 5 and 3.

In this study, the initial fuzzy inference system (FIS) with Gaussian membership function was built by grid partitioning method. Then, the FIS was trained to update the membership function parameters by using the hybrid optimization method. The number of epochs and error tolerance

Table 2 F-test results

\begin{tabular}{lccccc}
\hline & $\begin{array}{l}\text { Degree of free- } \\
\text { dom }(d f)\end{array}$ & $\begin{array}{l}\text { Sum of squares } \\
(\mathrm{SS})\end{array}$ & Mean square & $F$ & Significance $(p)$ \\
\hline Regression & 2 & 39.65 & 19.83 & 387.88 & $1,50 \mathrm{E}-25$ \\
Residual & 38 & 1.94 & 0.05 & & \\
Total & 40 & 41.59 & & & \\
\hline
\end{tabular}


Table 3 Optimization of hyperparameters

\begin{tabular}{llll}
\hline $\begin{array}{l}\text { Number of membership function } \\
\text { Membership func- } \\
\text { tion type }\end{array}$ & Input 1 & Input 2 & Training RMSE \\
\hline Gaussian & 5 & 3 & 0.0085 \\
& 4 & 4 & 0.009 \\
& 3 & 3 & 0.011 \\
Triangular & 2 & 2 & 0.022 \\
& 5 & 3 & 0.01 \\
& 4 & 4 & 0.009 \\
& 3 & 3 & 0.015 \\
Trapezodial & 2 & 2 & 0.028 \\
& 5 & 3 & 0.012 \\
& 4 & 4 & 0.015 \\
& 3 & 3 & 0.015 \\
& 2 & 2 & 0.03 \\
\hline
\end{tabular}

parameters used in training stage were selected as 500 and 0 , respectively. The structure of ANFIS model used in this study is given in Fig. 2.

The prediction performance of ANFIS model and multivariate equation was assessed by using root-meansquare error (RMSE) and mean absolute percentage error (MAPE), Table 4. Both RMSE and MAPE values calculated
Table 4 The comparison of prediction performance of models

\begin{tabular}{lll}
\hline Model type & RMSE & MAPE \\
\hline ANFIS & 0,07 & 1,47 \\
Multiple regression & 2.29 & 29.25 \\
\hline
\end{tabular}

for multivariate regression are higher than the values obtained for ANFIS model. So it is clear from Table 4 that the prediction performance of ANFIS model is higher than multivariate regression analysis. This is mainly based on the possible representation of nonlinear relationships between the variables in ANFIS model.

3D surface created by ANFIS modeling is given in Fig. 3 . As it can be understood from Fig. $3, R_{\text {normalize }} / R_{\text {test }}$ ratio is increased due to increment in impact direction angle. However, this increment is highly changeable. While a lower increment can be seen for rebound values around 50, higher increment levels can be obtained for low rebound number values (such as between 20 and 30). On the other hand, there are two opposite trends for variation of $R_{\text {normalize }} / R_{\text {test }}$ due to variation of rebound number and impact direction. While the ratio is decreased due to decrement of rebound number for low impact direction angle values, the opposite trend is observed for high impact

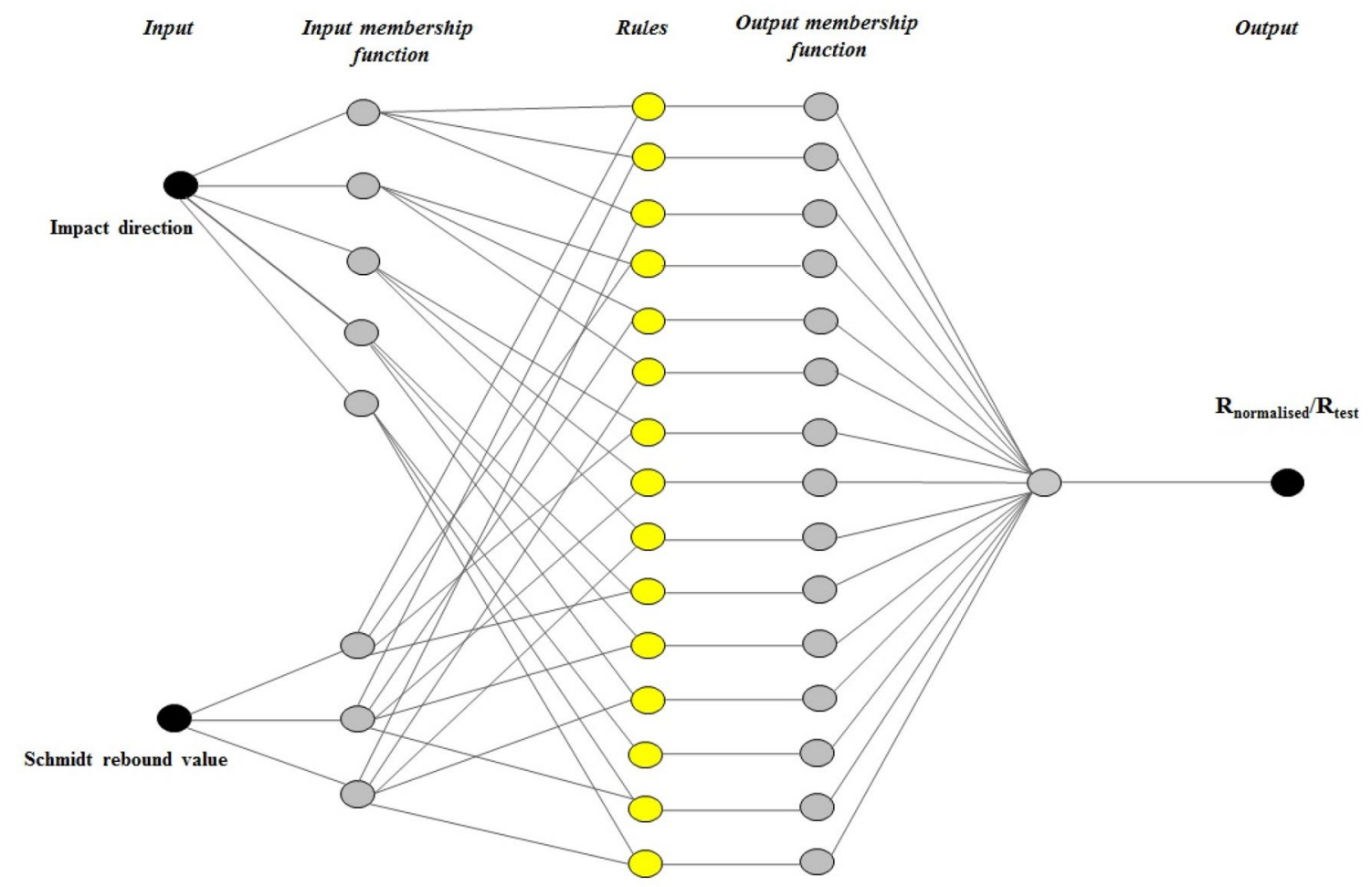

Fig. 2 The structure of ANFIS model 


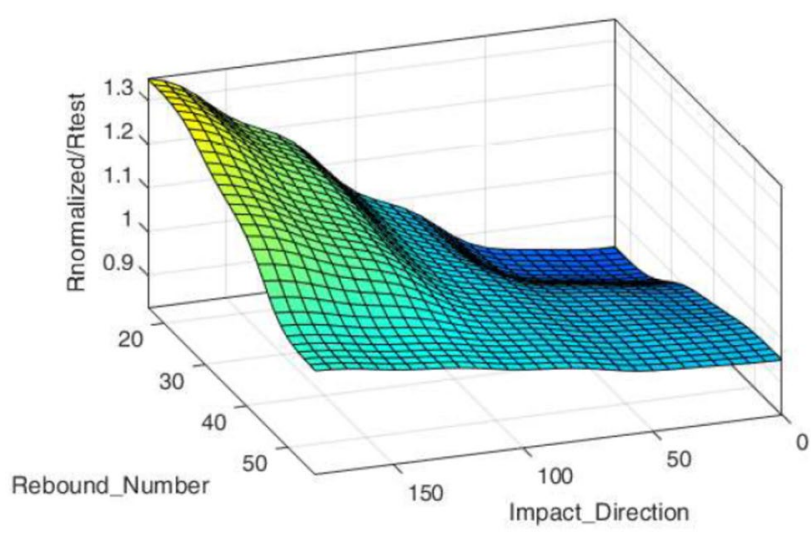

Fig. 3. 3D surface plots created by ANFIS modeling

direction angle values. So there is a extra deviation from the theoretical normalization formulation for the situation includes low rebound number and high impact direction angle. As stated by Basu and Aydın [5] the assumption used in normalization formula may not be satisfied for some weak and weathered rocks due to existence of difference energy absorbance levels.

The reason of this may deal with the variation of impact energy due to difference in impact direction. As it is mentioned by Basu and Aydın [5], the difference between the highest and lowest impact energy for L-type Schmidt hammer is approximately $0.1 \mathrm{Nm}$. This variation is based on the impact direction, and while highest value is obtained for $0^{\circ}\left(90^{\circ}\right.$ downward), lowest values are valid for $180^{\circ}\left(90^{\circ}\right.$ upward) impact direction. High impact energy induced for $0^{\circ}\left(90^{\circ}\right.$ downward) creates higher damage (plastic strain) than other impact directions for weak and porous rocks, so this is also effective on low rebound value in addition to gravitational forces. On the other hand, relatively low impact energy creates lower damage (and plastic strain) so the corresponding rebound value will be higher.

\section{Conclusions}

The effect of impact direction on the Schmidt hammer rebound values was investigated in this study. In general test results are compatible with the values calculated by suggested normalization formula. However, there is a small deviation for the tests with upward impact direction of weak rocks with highly porosity. Test results showed that the ratio between normalized rebound value and rebound value obtained from Schmidt hammer test is changeable due to variation on both impact direction and rock type. While the ratio is increased due to increment in impact direction angle from $0^{\circ}$ to $180^{\circ}$, the level of increment is highly changeable due to variation on rebound number.
On the other hand, in general, the ratio is inversely proportional to rebound number and the variation level depends on rock type. However, the prediction of the ratio is possible by using multivariate regression and adaptive neurofuzzy inference system with high sensitivity. Besides, the prediction performance of ANFIS model was determined as higher than the predictions derived by multivariate regression analysis.

\section{Compliance with ethical standards}

Conflict of interest The author declares that he has no conflict of interest.

\section{References}

1. Ansari MK, Ahmad M, Singh R, Singh TN (2015) Correlation between schmidt hardness and coefficient of restitution of rocks. J Afr Earth Sci 104:1-5

2. Armaghani DJ, Mohamad ET, Momeni E, Narayanasamy MS, Amin MFA (2015) An adaptive neuro-fuzzy inference system for predicting unconfined compressive strength and Young's modulus: a study on Main Range granite. Bull Eng Geol Environ 74:1301-1319

3. Ayday C, Göktan RM (1992) Correlations between L and N-type Schmidt hammer rebound values obtained during field testing. Eurock '92, London, Thomas Telford, pp 47-50

4. Aydin A, Basu A (2005) The Schmidt hammer in rock material characterization. Eng Geol 81:1-14

5. Basu A, Aydin A (2004) A method for normalization of Schmidt hammer rebound values. Int J Rock Mech Min Sci 41:1211-1214

6. Buyuksagis IS, Goktan RM (2007) The effect of Schmidt hammer type on uniaxial compressive strength prediction of rock. Int J Rock Mech Min Sci 44:299-307

7. Çelik SB, Çobanoğlu I (2019) Comparative investigation of Shore, Schmidt, and Leeb hardness tests in the characterization of rock materials. Environ Earth Sci 78:554

8. Gilardi G, Sharf I (2002) Literature survey of contact dynamics modelling. Mech Mach Theory 37:1213-1239

9. Gokceoglu C, Yesilnacar E, Sonmez H, Kayabasi A (2004) A neurofuzzy model for modulus of deformation of jointed rock masses. Comput Geotech 31(5):375-383

10. ISRM (2007) The complete ISRM suggested methods for rock characterization, testing and monitoring: 1974-2006. Suggested methods prepared by the commission on testing methods. In: Ulusay R, Hudson JA (eds) Compilation arranged by the ISRM Turkish National Group. ISRM, Ankara

11. ISRM (2015) The ISRM Suggested methods for rock characterization, testing and monitoring: 2007-2014. In: Ulusay R (ed). Springer, Switzerland, 293p

12. Jalali SH, Heidari M, Mohseni H (2017) Comparison of models for estimating uniaxial compressive strength of some sedimentary rocks from qom formation. Environ Earth Sci 76:753

13. Jang JSR, Sun CT (1995) Neuro-fuzzy modeling and control. Proc IEEE 83(3):378-406

14. Jing $H$, Rad HM, Hasanipanah M, Armaghani DJ, Qasem SN (2020) Design and implementation of a new tuned hybrid intelligent model to predict the uniaxial compressive strength of the rock using SFS-ANFIS. Eng Comput. https://doi.org/10.1007/ s00366-020-00977-1 
15. Li X, Rupert G, Summers A, Santi P, Li D (2000) Analysis of impact hammer rebound to estimate rock drillability. Rock Mech Rock Eng 33:1-13

16. Li X, Zhou Z, Zhao F, Zuo Y, Ma C, Ye Z, Hong L (2009) Mechanical properties of rock under coupled static-dynamic loads. J Rock Mech Geotech Eng 1(1):41-47

17. Mathur N, Glesk I, Buis A (2016) Comparison of adaptive neuro-fuzzy inference system (ANFIS) and gaussian processes for machine learning (GPML) algorithms for the prediction of skin temperature in lower limb prostheses. Med Eng Phys 38(10):1083-1089

18. Mathworks (2019) Fuzzy Logic Toolbox ${ }^{T M}$ User's Guide. The MathWorks, Inc.

19. Mishra RN, Mohanty KB (2016) Real time implementation of an ANFIS-based induction motor drive via feedback linearization for performance enhancement. Eng Sci Technol, Int J 19:1714-1730

20. Peng B (2000) Rockfall trajectory analysis-parameter determination and application. Dissertation, University of Canterbury.

21. Petkovic B, Petkovic D, Kuzman B (2020) Adaptive neuro fuzzy predictive models of agricultural biomass standard entropy and chemical exergy based on principal component analysis. Bioref, Biomass Conv. https://doi.org/10.1007/s13399-020-00767-1
22. Rezazadeh S, Mehrabi M, Pashaee T, Mırzaee I (2012) Using adaptive neuro-fuzzy inference system (ANFIS) for proton exchange membrane fuel cell (PEMFC) performance modeling. J Mech Sci Technol 26:3701-3709

23. Szilagyi K (2013) Rebound surface hardness and related properties of concrete. Dissertation, Budapest University Of Technology And Economics.

24. Umrao RK, Sharma LK, Singh R, Singh TN (2018) Determination of strength and modulus of elasticity of heterogenous sedimentary rocks: An ANFIS predictive technique. Measurement 126:194-201

25. YIlmaz I, Sendir H (2002) Correlation of Schmidt hardness with unconfined compressive strength and Young's modulus in gypsum from Sivas (Turkey). Eng Geol 66:211-219

26. Zhang W, Zhang R, Wu C, Goh ATC, Lacasse S, Liu Z, Liu H (2020) State-of-the-art review of soft computing applications in underground excavations. Geosci Front 11:1095-1106

Publisher's Note Springer Nature remains neutral with regard to jurisdictional claims in published maps and institutional affiliations. 